\title{
New Zinc Phosphates Decorated by Imidazole-Containing Ligands
}

Jian Fan, Carla Slebodnick, Ross Angel, Brian E. Hanson

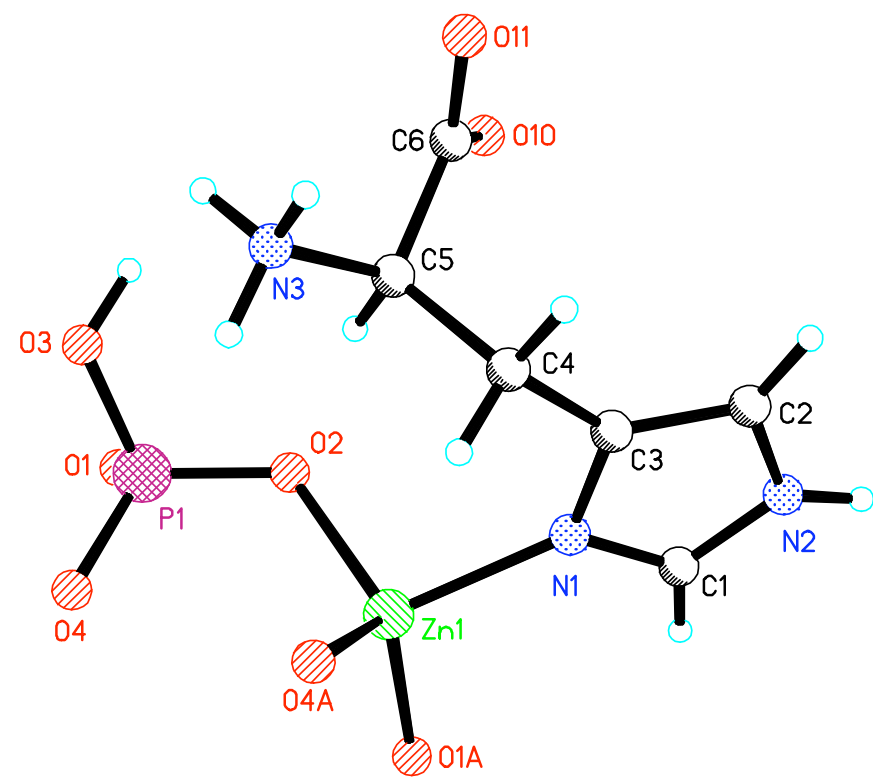

Figure S1. The asymmetric unit of compound 1 structure showing the atom labeling scheme. Two additional symmetry-related atoms are indicated by O1A and O4A.
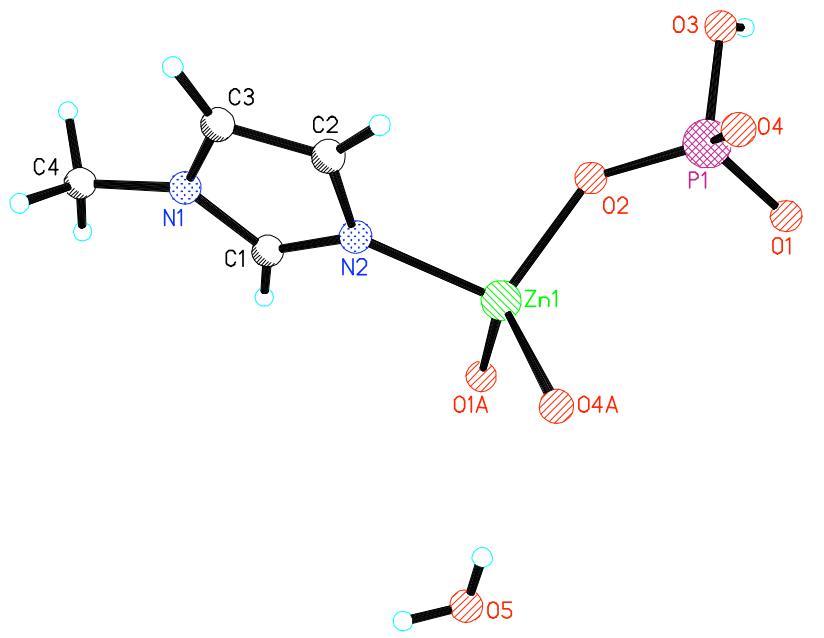

Figure S2. Fragment of $\left[\mathrm{Zn}\left(\mathrm{HPO}_{4}\right)\left(\mathrm{C}_{4} \mathrm{H}_{6} \mathrm{~N}_{2}\right)\right] \cdot \mathrm{H}_{2} \mathrm{O}$ (2) structure showing the atom labeling scheme. Symmetry-related atoms are indicated by O1A and O4A. 


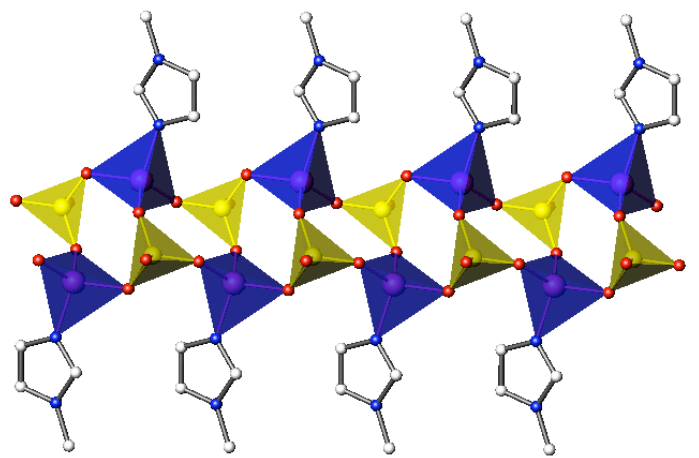

Figure S3. Polyhedral representation of $\left[\mathrm{Zn}\left(\mathrm{HPO}_{4}\right)\left(\mathrm{C}_{4} \mathrm{H}_{6} \mathrm{~N}_{2}\right)\right] \cdot \mathrm{H}_{2} \mathrm{O}$ (2) ladder structure showing the connectivity of the $\mathrm{PO}_{4}$ (yellow) and $\mathrm{ZnO}_{3} \mathrm{~N}$ (blue) polyhedra to 4-ring loops.

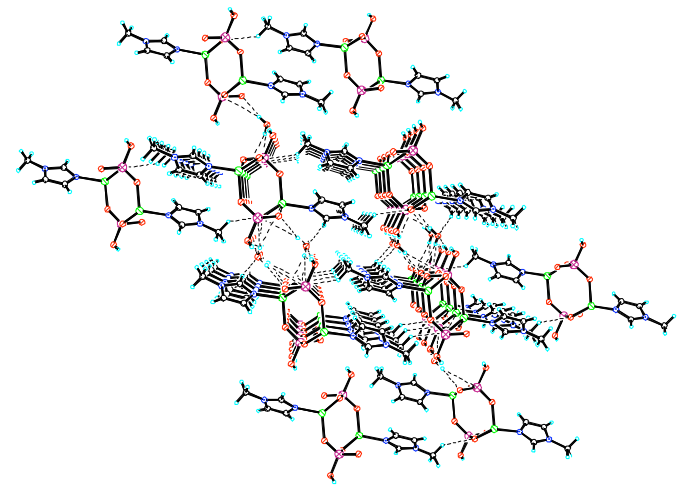

Figure S4. Packing diagram of 2 with the hydrogen bonding indicated by dashed lines.

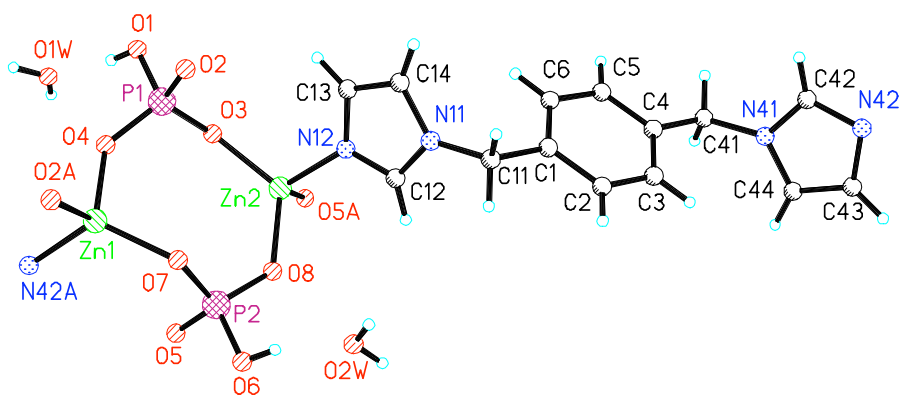

Figure S5. The asymmetric unit of compound 3 structure showing the atom labeling scheme. Three additional symmetry-related atoms are indicated by $\mathrm{O} 2 \mathrm{~A}, \mathrm{~N} 42 \mathrm{~A}$ and $\mathrm{O} 5 \mathrm{~A}$. 


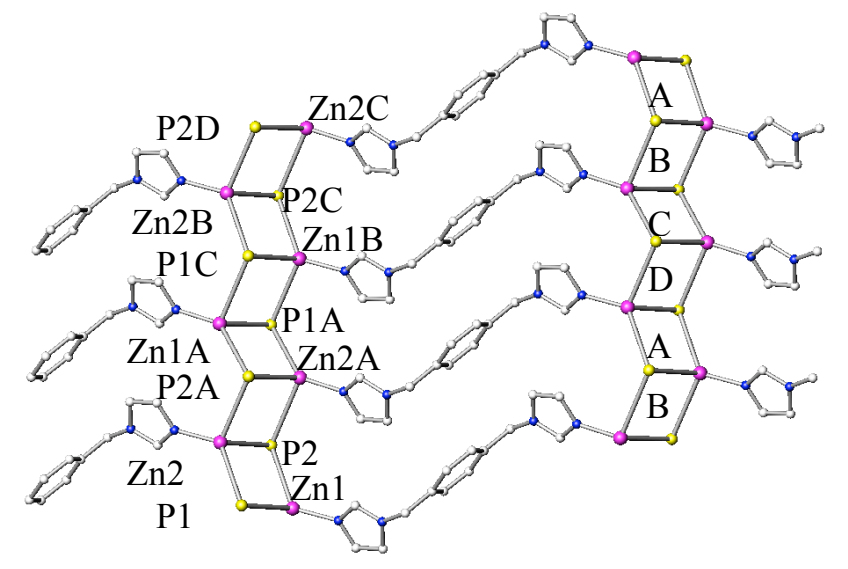

Figure S6. $\quad$ zigzag arrangement of 4-rings with Zn-O-P linkage drawn by a single line in 3.

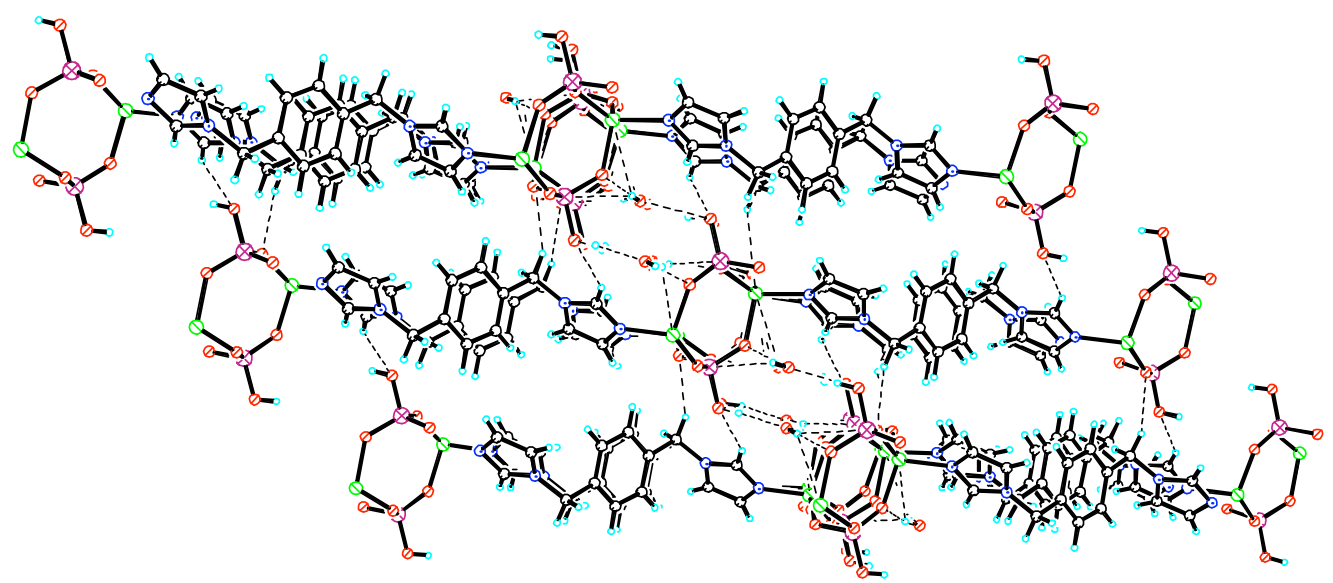

Figure S7. Packing diagram of 3 with the hydrogen bonding indicated by dashed lines. 


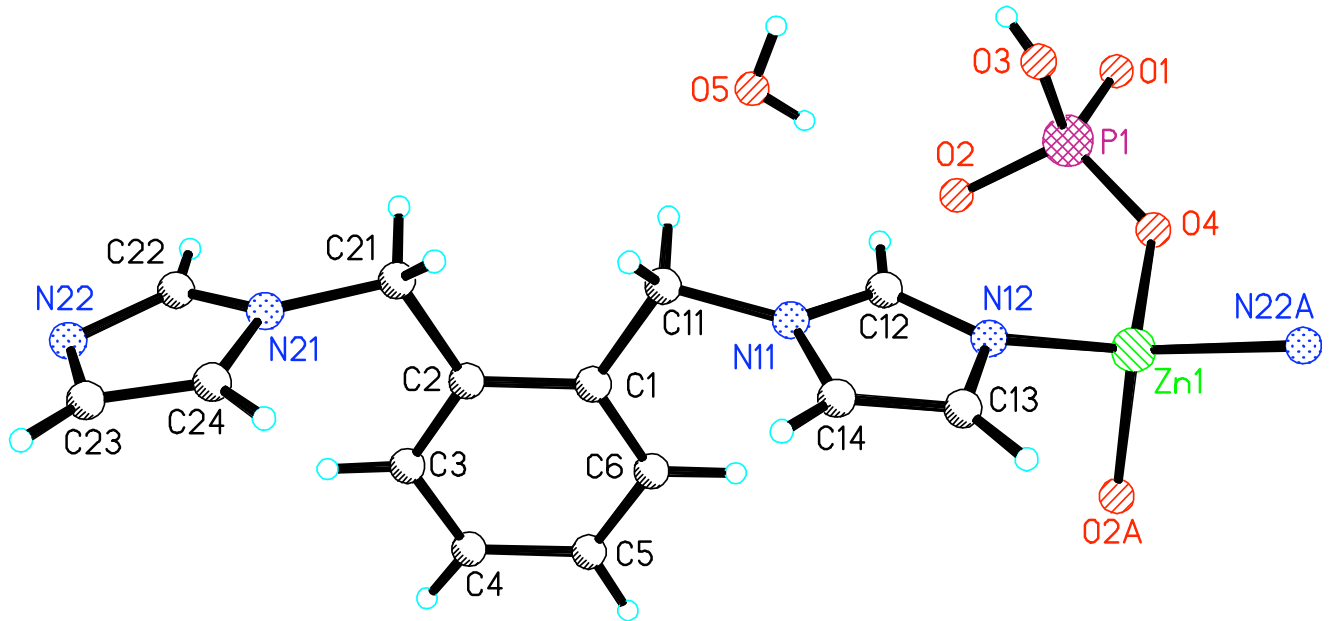

Figure S8. The asymmetric unit of compound $\mathbf{4}$ structure showing the atom labeling scheme. Two additional symmetry-related atoms are indicated by N22A and O2A.

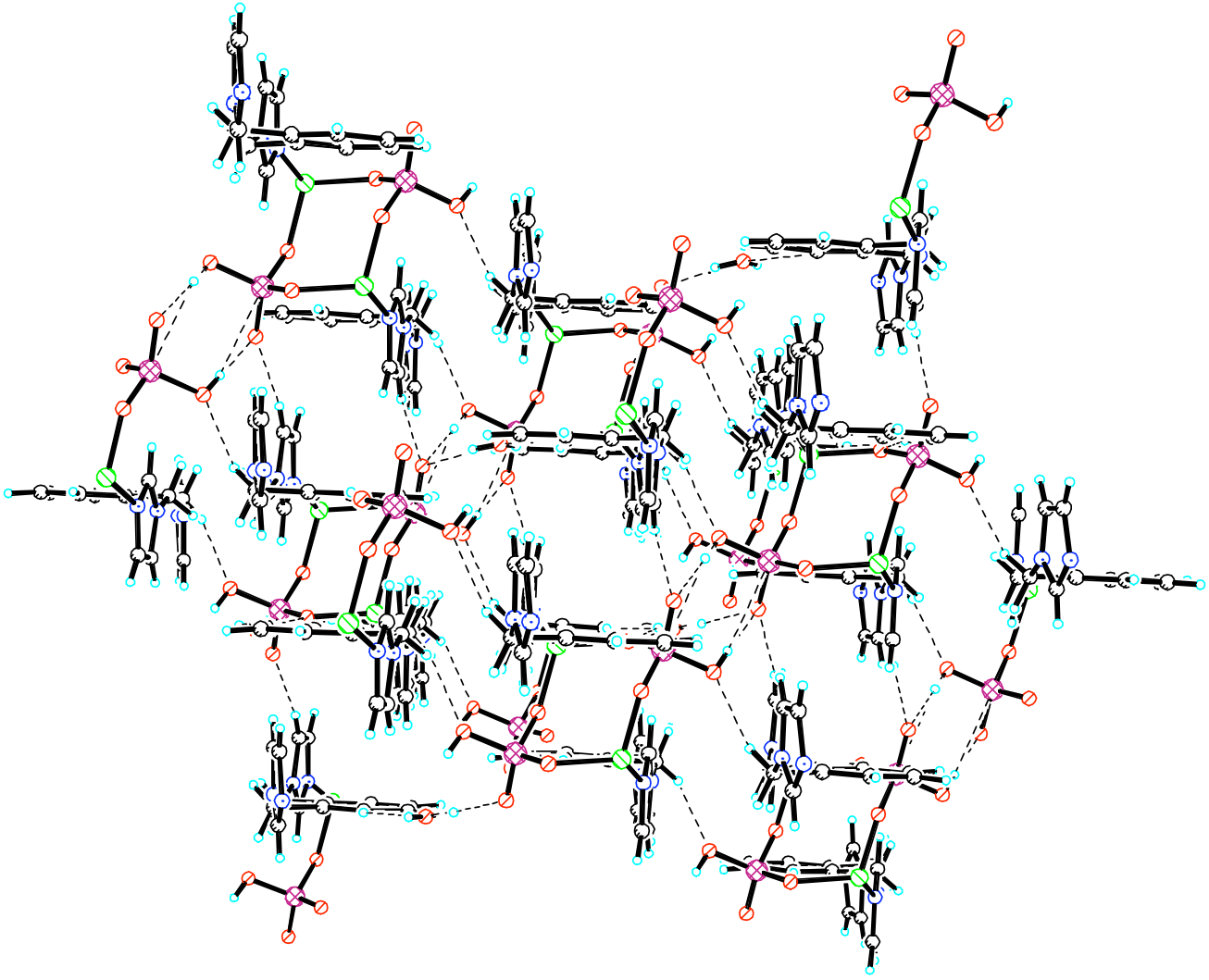

Figure S9. Crystal packing diagram for compound 4. Dashed lines represent the various possibly hydrogen-bond interactions. 